\title{
Implications for the mammalian sialidases in the physiopathology of skeletal muscle
}

\author{
Alessandro Fanzani ${ }^{*}$, Alessandra Zanola ${ }^{1}$, Fiorella Faggi ${ }^{1}$, Nadia Papini ${ }^{2}$, Bruno Venerando ${ }^{2}$, Guido Tettamanti ${ }^{3}$, \\ Maurilio Sampaolesi ${ }^{4,5^{*}}$ and Eugenio Monti ${ }^{1 *}$
}

\begin{abstract}
The family of mammalian sialidases is composed of four distinct versatile enzymes that remove negatively charged terminal sialic acid residues from gangliosides and glycoproteins in different subcellular areas and organelles, including lysosomes, cytosol, plasma membrane and mitochondria. In this review we summarize the growing body of data describing the important role of sialidases in skeletal muscle, a complex apparatus involved in numerous key functions and whose functional integrity can be affected by various conditions, such as aging, chronic diseases, cancer and neuromuscular disorders. In addition to supporting the proper catabolism of glycoconjugates, sialidases can affect different signaling pathways by desialylation of many receptors and modulation of ganglioside content in cell membranes, thus actively participating in myoblast proliferation, differentiation and hypertrophy, insulin responsiveness and skeletal muscle architecture.
\end{abstract}

Keywords: Sialidases, Gangliosides, Glycoproteins, Myogenesis, Skeletal muscle

\section{Review}

The family of sialidases

Sialidases or neuraminidases (EC 3.2.1.18, systematic name: acetylneuraminyl hydrolase) are glycohydrolases widely distributed in nature, from viruses and microorganisms such as bacteria, protozoa and fungi, to vertebrates [1,2]. They catalyze the removal of the acidic sugar sialic acid from a great variety of gangliosides and glycoproteins, generally termed glycoconjugates, which are mainly exposed on the cell surface or are secreted in the extracellular matrix (ECM) [3]. The particular chemical structure, the terminal position on oligosaccharide antennas and the negative charge of sialic acid residues confer special structural properties to glycoconjugates, accounting for their biological relevance as key regulators of molecular and cellular interactions [4]. Depending on their ability to act on $\alpha-(2 \rightarrow 3)-, \alpha-(2 \rightarrow 6)-, \alpha-(2 \rightarrow 8)-$ glycosidic linkages of terminal sialic acid residues, or on

\footnotetext{
*Correspondence: fanzani@med.unibs.it; maurilio.sampaolesi@med.kuleuven. be; monti@med.unibs.it

${ }^{1}$ Department of Biomedical Sciences and Biotechnologies and

Interuniversitary Institute of Myology (IIM), University of Brescia, Viale Europa

11, 25123, Brescia, Italy

${ }^{4}$ Stem Cell Research Institute, University Hospital Gasthuisberg, Herestraat 49, 3000, Leuven, Belgium

Full list of author information is available at the end of the article
}

$\alpha$-(2 $\rightarrow 8)$-sialosyl linkages in oligo- and poly-sialic acids, sialidases are subdivided into exo- or endo-sialidases, respectively $[2,4]$. Since the first cloning of a mammalian sialidase in 1993 boosted the research on these enzymes [5], four distinct genes have been identified, encoding the lysosomal NEU1, the cytosolic NEU2, the plasma membrane-associated NEU3 and the mithocondrial/ERassociated NEU4 types, as summarized in various general reviews [2,6-8]. All of them behave as exo-sialidases and have a significant degree of homology, sharing with microbial sialidases typical amino acid motifs, such as the $\mathrm{Y}$ (F)RI(V)P motif in N-terminus and the so called Asp boxes $(\operatorname{SxDxGxx} \Phi$, where $\Phi$ stands for an aromatic residue) along the primary structure [2]. Over the past two decades, the involvement of NEU1, NEU2 and NEU3 in the physiopathology of skeletal muscle has clearly emerged from different studies, emphasizing that these enzymes may affect the life of muscle cells by modifying the cell content of sialylated lipids and proteins.

\section{The substrates of sialidases: gangliosides and glycoproteins}

To understand the role of sialidases in skeletal muscle, we need to focus on their preferred substrates, which are gangliosides and glycoproteins. Gangliosides are acidic 
glycosphingolipids most abundant in the nervous system [9-11], but also present in skeletal muscle [12-16]. They are anchored on the outer leaflets of cell surfaces, with the sphingosine and fatty acid chains of the ceramide moiety embedded in the plasma membrane and the sugar oligosaccharide chain with terminal sialic acid(s) protruding toward the extracellular surface [17]. Gangliosides are involved in a plethora of physiological processes, such as cell-cell recognition and adhesion [18] and regulation of signal transduction in caveolae [19], lipid rafts [20] and glycosphingolipid-enriched microdomains [21]. They are also involved in the pathology of many diseases, such as the Guillain-Barre syndrome caused by an auto-immune response to surface gangliosides [22], influenza [23], some lysosomal storage diseases including Tay-Sachs disease (GM1 gangliosidosis), Sandhoff disease (GM2 gangliosidosis), sialidosis and galactosialidosis $[24,25]$, an infantile-onset symptomatic epilepsy syndrome caused by ganglioside GM3 deficiency [26], type 2 diabetes [27] and Alzheimer's disease [28,29]. Interestingly, altered GM3 levels have been recently found in the Hereditary Inclusion Body Myopathy (HIBM, also known as Distal Myopathy with Rimmed Vacuoles), a unique autosomal recessive muscle disorder characterized by adult-onset of muscle weakness in upper and lower limbs [30]. At the molecular level, gangliosides may participate in the composition and organization of membranes [31] and serve as modulators for several receptor proteins, usually limiting their activities. Ganglioside GM3, one of the essential components of plasma membrane rafts [32], is a negative regulator of insulin receptor (IR), as mice lacking GM3 display enhanced insulin sensitivity [33]. In addition, the coordinate enzymatic activity of sialidases and other glycohydrolases toward gangliosides may generate bioactive sphingolipids, such as ceramide, sphingosine and sphingosine-1-phosphate $[34,35]$, which have a variety of important effects on the activation of muscle resident stem cells, regulation of contractile properties, insulin responsiveness and muscle fiber nourishment [36].

Beyond the gangliosides, sialidases recognize and desialylate glycoproteins involved in various functions, thus influencing many processes in different cell types [37]. Protein glycosylation may be of great importance during myogenesis, as confirmed by the fact that its inhibition impairs the fusion of myoblasts [38], but it is particularly important to preserve the integrity of musculoskeletal tissues in the post-natal age. In this regard, it is well accepted that the aberrant glycosylation on the mucin domain of $\alpha$-dystroglycan, a member of the dystrophin-associated glycoprotein (DAG) complex $[39,40]$, is associated with many forms of muscular dystrophy [40-43], commonly referred to as Dystroglycanopathies [44-46]. Recently, it has been shown that sialidase NEU1 deficiency causes muscle degeneration due to lack of processing toward yet unknown protein substrates [47], thus underlining the importance of sialidases in preserving the integrity of skeletal muscle by regulation of protein glycosylation.

Finally, free unbounded sialic acids are considered as regulators that modulate the function of several voltagegated potassium and sodium channels responsible for the generation of action potentials in myofibers, cardiomyocytes and neurons $[48,49]$. On the basis of these preliminary observations, the ability of sialidases to modulate the cell contents of sialylated molecules have important consequences on muscle homeostasis, as described more in detail below.

\section{Functional role of sialidases in skeletal muscle}

The following sections briefly summarize the main biochemical features and biological functions of NEU1, NEU2 and NEU3 and then discuss in detail their role in skeletal muscle (see also Table 1 and Figure 1), with the exception of NEU4 that, at present, seems to be less involved in muscle development and/or physiology.

\section{Lysosomal sialidase NEU1}

NEU1 is a pivotal enzyme required to initiate the degradation of sialo-glycoconjugates in lysosomes [50], with preference for oligosaccharide and glycopeptide substrates [51], even if the protein can hydrolyze gangliosides in the presence of detergents or the sphingolipid activator Saposin B [52,53]. Newly synthesized NEU1 is transported to lysosomes, where is complexed with $\beta$-galactosidase ( $\beta-G A L)$ and the serine carboxypeptidase protective protein/cathepsin A (PPCA), the latter being specifically required for its catalytic activity [54]. Two genetically distinct lysosomal storage diseases are associated with NEU1 deficiency: sialidosis (OMIM 256550), which results from structural mutations at the NEU1 locus on chromosome 6p21 [55], and galactosialidosis (OMIM 256540), which is caused by a primary defect of PPCA, leading to secondary and combined deficiencies of NEU1 and $\beta$-GAL $[56,57]$. Depending on the levels of residual enzyme activity, NEU1 deficiency promotes a progressive lysosomal accumulation of sialylated glycopeptides, gangliosides and oligosaccharides in several cell types, leading to a broad spectrum of clinical manifestations such as abnormal somatic features, severe neurologic involvement and muscular dysfunction due to muscle hypotonia, atrophy, and osteoskeletal deformities [58]. These clinical symptoms have suggested an important role for NEU1 in muscle homeostasis, as deduced from the analysis of an inbred SM/J mouse strain with defects in NEU1 expression [59-61] and from the muscular phenotype of NEU1-/- mice [47]. Unlike dystrophic muscles, commonly characterized by sarcolemmal damage, intense inflammatory response, cellular necrosis and repeated cycles of muscle regeneration, the muscle pathology of NEU1-/- mice was derived from 
Table 1 Sialidases in skeletal muscle

\begin{tabular}{|c|c|c|c|c|}
\hline & NEU1 & NEU2 & NEU3 & NEU4 \\
\hline $\begin{array}{l}\text { Human chromosomal } \\
\text { localization }\end{array}$ & $6 \mathrm{p} 21.31$ & $2 q 37.1$ & $11 q 13.5$ & $2 q 37.3$ \\
\hline $\begin{array}{l}\text { Human disorders due to } \\
\text { inherited deficiency }\end{array}$ & Sialidosis and Galactosialidosis [55] & none & none & none \\
\hline Sialidase animal models & $\begin{array}{l}\text { NEU1 -/- mice exhibit muscle } \\
\text { degeneration [47] }\end{array}$ & none & $\begin{array}{l}\text { Transgenic NEU3 mice } \\
\text { develop insulin resistance [126] }\end{array}$ & none \\
\hline Expression in myoblasts & In vivo and in vitro $[47,83,84]$ & $\begin{array}{l}\text { In vitro }[5,89,92,93,97-99 \\
103,104,107]\end{array}$ & In vivo and in vitro $[126,137]$ & not detected \\
\hline \multirow[t]{4}{*}{$\begin{array}{l}\text { Role proposed in } \\
\text { muscle cells }\end{array}$} & $\begin{array}{l}\text { NEU1 regulates the ECM deposition } \\
\text { in skeletal muscle by limiting the } \\
\text { lysosomal exocytosis in the } \\
\text { fibroblasts sorrounding } \\
\text { the myofibers [47] }\end{array}$ & $\begin{array}{l}\text { NEU2 silencing prevents } \\
\text { myoblast differentiation of } \\
\text { rat L6 myoblasts [99] }\end{array}$ & $\begin{array}{l}\text { NEU3 behaves as a negative } \\
\text { regulator of glucose uptake [126] }\end{array}$ & \\
\hline & $\begin{array}{l}\text { NEU1 can desialylate both IR or } \\
\text { IGF1R and influence insulin } \\
\text { responsiveness [82] }\end{array}$ & $\begin{array}{l}\text { NEU2 over-expression } \\
\text { enhances C2C12 } \\
\text { differentiation [98] }\end{array}$ & $\begin{array}{l}\text { NEU3 is involved in } \mathrm{C}_{2} \mathrm{C} 12 \\
\text { myoblast fusion by controlling } \\
\text { the levels of GM3 [137] }\end{array}$ & \\
\hline & $\begin{array}{l}\text { NEU1 expression increases } \\
\text { during the early stages of } \\
\text { mouse } \mathrm{C} 2 \mathrm{C} 12 \text { myoblast } \\
\text { differentiation [83] }\end{array}$ & $\begin{array}{l}\text { NEU2 expression increases } \\
\text { through the PI3K/AKT pathway } \\
\text { during differentiation and } \\
\text { hypertrophy of C2C12 } \\
\text { myotubes }[103,104]\end{array}$ & $\begin{array}{l}\text { NEU3 over-expression delays } \\
\text { differentiation but finally } \\
\text { promotes the formation of } \\
\text { hypertrophic myotubes [138] }\end{array}$ & \\
\hline & $\begin{array}{l}\text { NEU1 over-expression } \\
\text { impairs C2C12 } \\
\text { differentiation [84] }\end{array}$ & $\begin{array}{l}\text { NEU2 is degraded through } \\
\text { an autophagic-dependent } \\
\text { pathway during atrophy of } \\
\text { C2C12 myotubes }[104,107]\end{array}$ & & \\
\hline $\begin{array}{l}\text { Muscle-derived tumors: } \\
\text { rhabdomyosarcomas }\end{array}$ & - & $\begin{array}{l}\text { NEU2 expression is undetectable } \\
\text { in the human embryonal RD } \\
\text { cells [109] }\end{array}$ & & \\
\hline
\end{tabular}

an excessive lysosomal exocytosis in the fibroblasts surrounding the basal lamina, leading to increased secretion of proteolytic lysosomal cathepsins and metalloproteinases that facilitate fibroblast proliferation and infiltration within the juxtaposed myofibers [47]. Lysosomal exocytosis, a calcium-dependent mechanism that allows the fusion of specialized lysosomes in the plasma membrane and the release of their luminal content extracellularly [62-65], is required during various physiological and pathological processes, such as the repair of the plasma membrane, the elimination of pathogenic bacteria or the release of HIV from infected cells [66-69]. In this context, NEU1 was previously found to negatively regulate the lysosomal exocytosis in hematopoietic cells by processing the lysosomalassociated membrane protein-1 (LAMP-1) protein [70]. In skeletal muscle NEU1 plays a critical role in the control of ECM deposition by limiting the lysosomal exocytosis in fibroblasts surrounding the myofibers, although the molecular targets underlying this mechanism remain to be elucidated. It is worth remembering that dystrophic muscles are usually characterized by the occurrence of fibrotic areas worsening the clinical outcome of patients. In this regard, it may be important from a therapeutic point of view to assess whether NEU1 may possibly influence by receptor desialylation certain signaling pathways playing a key role in muscle fibrosis, such as those dependent on the transforming growth factor beta (TGF- $\beta$ ) ligands [71-75]. Beyond the lysosomes, NEU1 can indeed be targeted to the cell surface in a multiprotein complex [76], playing an active role in the desialylation of several canonical and non-canonical cell receptors [77,78]. For instance, NEU1-mediated desialylation of integrin $\beta 4$ leads to metastasis suppression in colon cancer $[79,80]$, whereas in arterial smooth muscle cells the NEU1dependent desialylation of both platelet-derived growth factor receptor (PDGFR) and insulin-like growth factor-1 receptor (IGF1R) lowered their intracellular signals, thereby diminishing cell proliferation [81]. In agreement with this evidence, the NEU1-mediated desialylation of both insulin receptor (IR) or IGF1R in L6 skeletal myoblasts leads to an increased or decreased cell proliferation in response to low or high concentrations of insulin, respectively, suggesting that NEU1 activity may influence glucose uptake in myoblasts [82].

As well as having a central role in the control of muscle architecture and responsiveness, NEU1 has been implicated in the regulation of myogenesis, as deduced from different in vitro studies. In this respect, it was shown that the NEU1 promoter region contains a CCAAT box and four E-boxes which serve to drive its expression through a MyoD-dependent mechanism [83]. In particular, NEU1 expression is closely and temporally 


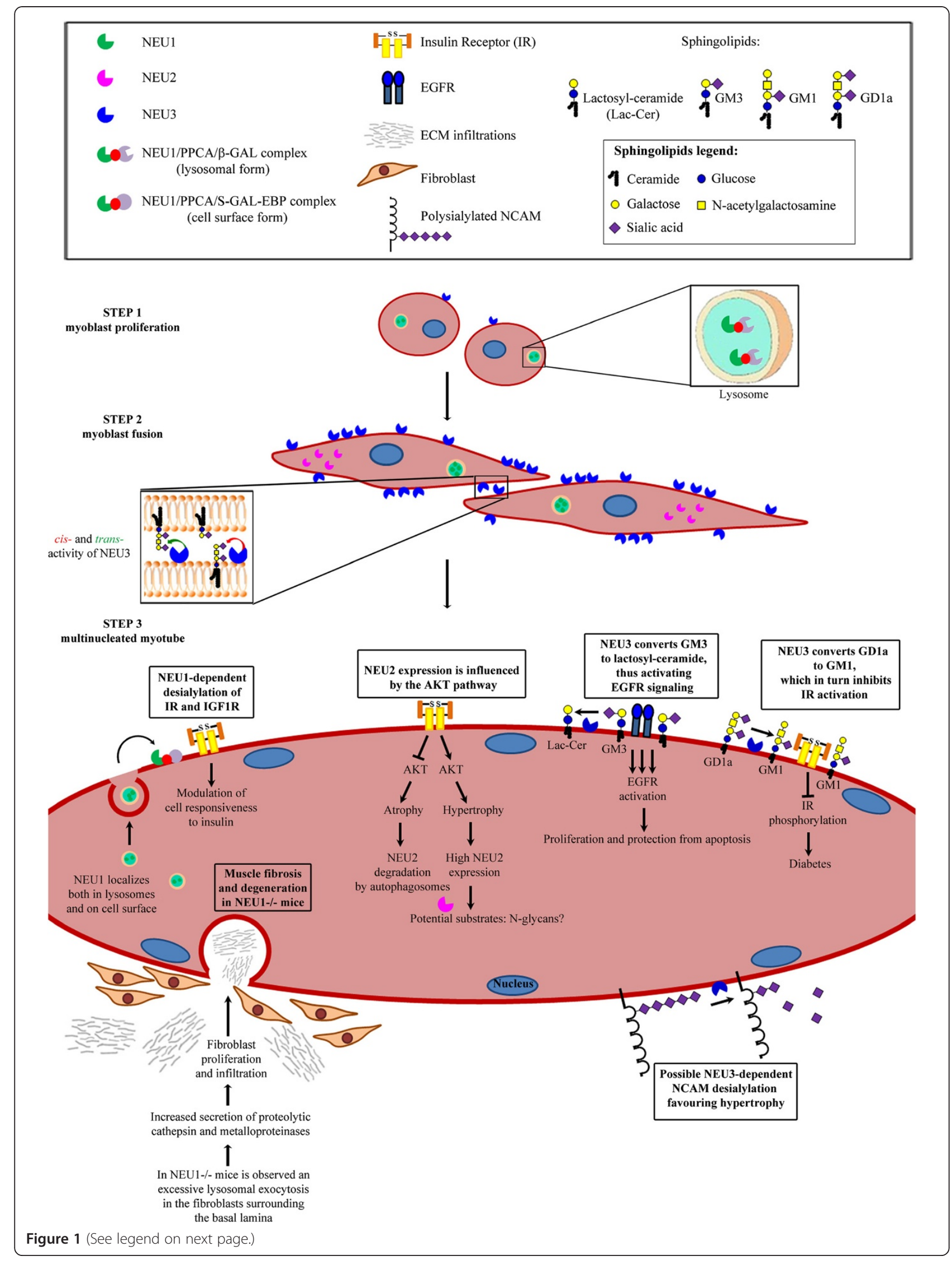


(See figure on previous page.)

Figure 1 Cartoon depicting the role of sialidases during the multistep process of myogenesis. STEP 1: During myoblast proliferation, NEU1 is complexed with PPCA and $\beta$-GAL and its activity is mainly detectable within lysosomes, whereas plasma membrane-associated NEU3 is present at low levels. On the other hand, the cytosolic NEU2 is absent. STEP 2: Myoblast fusion is characterized by an early and transient increase of NEU1 expression as well as by a long-lasting increment of both NEU2 and NEU3 expression, the latter being involved in cell-cell recognition by working on gangliosides resident on the same cell (cis-activity) or on adjacent cells (trans-activity), as shown in the enlarged box. STEP 3: In differentiated myotubes, NEU1 participates in the degradation of sialo-glycoconjugates in lysosomes but it is also targeted to the cell surface, where it may desialylate IR and IGF1R, thus affecting their responsiveness to insulin. Since NEU1 limits the lysosomal exocytosis in the fibroblasts surrounding the myofibers, NEU1 -/- mice exhibit muscle degeneration due to infiltration of connective tissues. In the cytosol of myotubes, NEU2 expression is modulated mainly through the AKT pathway during hypertrophy and atrophy. In this compartment, cytosolic N-glycans may represent suitable substrates of this enzyme. At the plasma membrane, NEU3 positively affects EGFR signaling by converting GM3 to lactosyl-ceramide, while it blocks the IR activity by conversion of GD1a to GM1. Cell surface sialylated molecules, such as NCAM, may be a target of NEU3 activity. Note that depiction of sugar chains corresponds to the simplified style used in [144].

up-regulated during the early stages of skeletal muscle differentiation, while it is down-regulated in the late stages through repression of the promoter activity by a MEK1-dependent mechanism, suggesting that NEU1 levels must be finely tuned [84]. In support of this gene regulation, constitutive NEU1 over-expression impaired the differentiating process of $\mathrm{C} 2 \mathrm{C} 12$ myoblasts [84], suggesting that its constitutive over-activation may irreversibly affect the sialylation state and activity of some surface molecules involved in myogenesis, such as CD45, CD164 and the neural cell adhesion molecule (NCAM) [85-88].

Overall, we may conclude that NEU1 plays a pleiotropic role in skeletal muscle, encompassing the control of cell proliferation, differentiation and, above all, skeletal muscle architecture.

\section{Cytosolic sialidase NEU2}

In 1993 Miyagi et al. reported the first molecular cloning of a mammalian sialidase encoding the sialidase NEU2 [5], a cytosolic enzyme expressed predominantly in skeletal muscle [89] and, to a lesser extent, in liver [90] and thymus [91]. Two subsequent works confirmed that the human NEU2 enzyme, sharing a high degree of homology with the rodent forms, is expressed in skeletal muscle and shows a subcellular localization and biochemical properties typical of the soluble sialidases [92,93]. Protein crystallography studies revealed that the human NEU2 consists of a six bladed $\beta$-propeller [94], a structural organization that is typically conserved between viral and microbial sialidases [95]. Furthermore, a detailed kinetic characterization has indicated that NEU2 exhibits a broad substrate specificity toward gangliosides and several different glycoproteins [96]. On the basis of sequence homologies, it is plausible to assume that the other mammalian sialidases share with NEU2 a conserved structural organization and a similar broad substrate specificity. Because of its almost exclusive expression in musculoskeletal tissues, two initial studies carried out in 1995 [97] and later in 2003 [98] pointed out the NEU2 involvement during differentiation of skeletal myoblasts in vitro. In this regard, an increased NEU2 gene transcription in rat L6 myoblasts appeared to be dependent on the presence in the promoter region of two pairs of E-box sequences, which are known binding sites for muscle-specific transcription factors involved in differentiation [97]. Subsequently, a similar transcriptional NEU2 up-regulation was observed during differentiation of mouse $\mathrm{C} 2 \mathrm{C} 12$ myoblasts [98]. Indeed, a long-lasting increase of NEU2 enzymatic activity can be detected in the cytosolic fractions of myoblasts that are committed to differentiate $[98,99]$. These initial studies also discovered that altering NEU2 expression may influence the process of differentiation, as NEU2 suppression impaired the fusion process of L6 myoblasts [99], while over-expression of a rat form inhibited the proliferation and improved the differentiation in mouse $\mathrm{C} 2 \mathrm{C} 12$ myoblasts [98]. To gain further insights, NEU2 has been studied during hypertrophy and atrophy. In this regard, the hypertrophy of $\mathrm{C} 2 \mathrm{C} 12$ myotubes obtained via administration of IGF1 [100], vasopressin [101] or histone deacetylase inhibitor Trichostatin A [102] resulted in a significant increase in NEU2 transcriptional and enzymatic levels $[103,104]$. Moreover, such an increase is obtained through the activation of the PI3K/AKT signaling pathway, the master controller of the balance between protein synthesis and degradation in skeletal muscle [105,106]. In this regard, the increase of NEU2 activity assayed in hypertrophic $\mathrm{C} 2 \mathrm{C} 12$ myotubes as a result of the constitutive AKT signaling was particularly impressive [103], suggesting that NEU2 may cooperate as one of its downstream effectors in building skeletal muscle. In agreement with this evidence, the atrophy of myotubes induced by nutrient deprivation or treatment with the glucocorticoid dexamethasone was relative to the impaired activity of the PI3K/AKT pathway and was characterized by a macroautophagic-dependent degradation of NEU2 [104,107]. In this context, in vitro assays showed that NEU2 is sensitive to the proteolytic action of the lysosomal cathepsins B and L [107], two isoforms with prevalent expression in skeletal muscle [108]. Finally, it is interesting to note that NEU2 was also investigated in human RD cells [109], which are cancerous cells deriving 
from rhabdomyosarcomas, a class of pediatric soft-tissue tumors composed of cell elements committed toward a myoblast lineage [110-113]. NEU2 was undetectable in RD cells and their partial myogenic differentiation obtained using drug treatments was not sufficient to restore its expression [109]; this suggests that the loss of NEU2, contributing to the impaired myoblast differentiation, may favor the oncogenic process. Overall, this growing body of evidence underlines an important role of NEU2, although not fully understood, in the fusion of myoblasts and the growth of myofibers. In support of this notion, it is intriguing that the impaired muscle regeneration observed in the SJL mouse, a model for human dysferlinopathy, is characterized by NEU2 down-regulation [114]. With regard to its potential substrates, it is believed that they should preferentially be glycoproteins instead of gangliosides, given the cytosolic localization of the enzyme. In this respect, it is of interest that NEU2 may participate in the degradation of complex-type N-glycans in the cytosol of MKN7 and MKN45 stomach cancer cells [115]. N-linked glycosylation is the most common type of post-translational modification playing a central role in the onset of some muscular dystrophies [43,44,116], as confirmed by the fact that mutations in DPAGT1, an essential enzyme catalyzing the first committed step of $\mathrm{N}$-linked protein glycosylation, are responsible for a limbgirdle congenital myasthenic syndrome with tubular aggregates [117]. From this perspective, it is plausible that NEU2 may facilitate the process of myogenesis by ensuring the correct turn-over of glycosylated proteins through the processing of free oligosaccharides or misfolded glycoproteins that are released into the cytosol.

Altogether, these observations indicate that further investigation is required to understand the role of NEU2, also taking into account the fact that its expression in human muscles appears to be significantly lower in comparison to murine muscles.

\section{Plasma membrane-associated sialidase NEU3}

NEU3, originally described as plasma membrane ganglioside sialidase [118-121], is a peripheral or extrinsic membrane-associated enzyme that has the ability to work on gangliosides that are located on the same membrane (cis-activity) or on the membrane of adjacent cells (transactivity) [122,123], thus playing a central role in cell-cell interactions. As a result of NEU3 activity, the cell content of gangliosides decreases, leading to (i) a modification of the negative charge on glycocalix, (ii) a modulation of the cell content of bioactive lipids such as GM3, lactosylceramide, glucosyl-ceramide and ceramide $[10,34,35,124]$, (iii) a variation of the chemico/physical properties of lipid rafts whose clustering represents a pivotal step for membrane fusion during myogenesis [125] and (iv) a modulation of the activity of many canonical and non-canonical receptors, such as IR [126], epidermal growth factor receptor (EGFR) [127] and integrin $\beta 4$ [128]. Regarding the latter point, NEU3 has been proposed as a cancer marker, because its up-regulation was found to promote the suppression of cell apoptosis in human tumors by a mechanism dependent on the depletion of gangliosides and subsequent over-activation of mitogenic receptors [127-130]. At the plasma membrane, NEU3 specifically localizes in lipid rafts and caveolae [131,132], microdomains specialized in the recruitment of molecules required for insulin signaling [133]. Two distinct works have indeed shown that NEU3 configures as an important regulator of this signaling along the skeletal muscle/liver axis. In particular, in skeletal muscle, NEU3 behaves as a negative regulator of glucose uptake, as in response to insulin the enzyme was activated by tyrosine phosphorylation and association with the growth factor receptor-bound protein 2 (GRB2), leading to accumulation of GM1 and GM2 gangliosides which, in turn, reduced the IR phosphorylation [126]. Accordingly, increasing both NEU3 expression or GM1 and GM2 levels in the plasma membrane of L6 myocytes and 3T3-L1 adipocytes inhibited IR phosphorylation [126]. Notably, mice over-expressing the human NEU3 enzyme developed a diabetic phenotype associated with hyperinsulinemia, islets hyperplasia and increased beta-cell mass [126]. Unlike what was observed in skeletal muscle, liver NEU3 over-expression positively improved insulin sensitivity and glucose tolerance in C57BL/6 and insulinresistant KKAy mice by increased deposition of glycogen and triglycerides [134], suggesting that the effects of NEU3 on insulin responsiveness may differ between skeletal muscle and liver depending on the tissue-specific pattern of gangliosides.

Over the past years NEU3 has been characterized for its ability to enhance the activity of EGFR in two distinct ways, such as direct protein binding $[127,130]$ or depletion of ganglioside GM3 $[135,136]$. In fact, NEU3 was found to promote myogenic differentiation of $\mathrm{C} 2 \mathrm{C} 12$ myoblasts by specifically decreasing the amount of GM3, thereby allowing cell proliferation via EGFR signaling and protection from apoptotic stimuli [137]. In agreement with this evidence, NEU3 silencing led to an increased threshold of GM3 levels that caused EGFR inhibition, compromising the differentiation of $\mathrm{C} 2 \mathrm{C} 12$ cells [137]. On the other hand, another recent study from the same group showed that NEU3 over-expression in $\mathrm{C} 2 \mathrm{C} 12$ myoblasts resulted in a significant reduction of GM3 that initially slowed the differentiation by increasing cell proliferation, but then promoted the formation of hypertrophic myotubes [138]. This particular behavior could be explained by considering that the greater number of proliferating myoblasts derived from the enhanced EGFR signaling may be subsequently engaged in neoformed myotubes, which then display an increased number of myonuclei. In the same study [138], 
biochemical assays showed that NEU3 may cleave colominic acid, a linear $\alpha-(2 \rightarrow 8)$-linked polymer of sialic acid mirroring the negative antennas of NCAM, a molecule whose proper desialylation is crucial for myoblast fusion [88]. Based on these assumptions, it is intriguing to speculate that the hypertrophic behavior of NEU3-overexpressing myotubes could be related to the ability of NEU3 to desialylate specific surface molecules, such as NCAM.

Overall, NEU3 plays an important role in the control of insulin responsiveness, in addition to actively participating in the process of myogenesis by modulation of gangliosides and, presumably, other surface sialylated molecules involved in cell-cell recognition and fusion.

\section{Conclusions}

Skeletal muscles are supplied from the fusion of multiple cell elements during embryonic development $[139,140]$. During the entire lifespan, their size mass is characterized by continuous remodelling as a result of physical exercise, chronic illnesses such as HIV, sepsis, diabetes and cancer cachexia, neuromuscular disorders or aging (sarcopenia) [141-143]. Sialidases have long been recognized as catabolic enzymes that, working within different subcellular compartments, can ensure the proper turn-over of glycoconjugates by catalyzing the removal of sialic acids residues. Nevertheless, a growing body of recent literature indicates that sialidases can specifically influence a number of different signaling pathways by modifying the cell content of gangliosides and sialylated receptorial and nonreceptorial proteins. In skeletal muscle what we know is that the orchestrated expression of the lysosomal NEU1, cytosolic NEU2 and plasma-membrane NEU3 sialidases contributes to myoblast proliferation and differentiation, control of insulin responsiveness and regulation of tissue architecture by the correct assembly and deposition of ECM surrounding the myofibers, as schematically illustrated in Figure 1. However, there are many things we do not know about sialidases in various physiological and pathological conditions of skeletal muscle, and hopefully, cell and animal engineering tactics coupled with proteomics techniques will produce a more complete characterization of their substrates in order to fully understand their role.

In conclusion, we are confident that a more detailed understanding of the role of sialidases in skeletal muscle physiopathology may significantly contribute to open new exciting frontiers of basic and therapeutic exploration.

\section{Abbreviations}

B-GAL: Beta-galactosidase; DAG: Dystrophin-associated glycoprotein; DPAGT1: Dolichyl-phosphate (UDP-N-acetylglucosamine) $\mathrm{N}$ -

acetylglucosaminephosphotransferase 1; ECM: Extracellular matrix; EGFR: Epidermal growth factor receptor; GRB2: Growth factor receptor-bound protein 2; IGF1: Insulin-like growth factor-1; IGF1R: IGF1 receptor; IR: Insulin receptor; LAMP-1: Lysosomal-associated membrane protein-1; MEK1: MAPK extracellular signal-regulated kinase kinase; NCAM: Neural cell adhesion molecule; PDGFR: Platelet-derived growth factor receptor; PI3K AKT: Phosphoinositide-3-kinase/AKT; PPCA: Protective protein/cathepsin A; TGF- $\beta$ : Transforming growth factor-beta.

\section{Competing interests}

The authors declare that they have no competing interests.

\section{Authors' contributions}

AF and EM wrote the manuscript. AZ, FF, NP, BV, GT and MS edited the manuscript. All the authors read and approved the final manuscript.

\section{Acknowledgements}

This work was supported by the Associazione Amici per il Cuore-ONLUS, Chiari (Brescia) - Italy to AF and EM, Fondazione Cariplo grant to EM, Grant NEDD - Network Enabled Drug Design, Regione Lombardia to EM and University of Brescia research fund (ex 60\%) to AF and EM.

\section{Author details}

'Department of Biomedical Sciences and Biotechnologies and Interuniversitary Institute of Myology (IIM), University of Brescia, Viale Europa 11, 25123, Brescia, Italy. ${ }^{2}$ Department of Medical Biotechnology and Translational Medicine, University of Milan, Segrate, Milan, Italy. ${ }^{3}$ Laboratory of Stem Cell for Tissue Engineering, IRCCS Policlinico San Donato, San Donato Milanese, Milan, Italy. ${ }^{4}$ Stem Cell Research Institute, University Hospital Gasthuisberg, Herestraat 49, 3000, Leuven, Belgium. ${ }^{5}$ Human Anatomy Section, University of Pavia, Via Forlanini 8, 27100, Pavia, Italy.

Received: 25 July 2012 Accepted: 2 October 2012

Published: 1 November 2012

\section{References}

1. Saito M, Yu RK: Biochemistry and function of sialidases. In Biology of the Sialic Acids. Edited by Rosenberg A.: Plenum Press; 1995:261-313.

2. Monti E, Bonten E, D'Azzo A, Bresciani R, Venerando B, Borsani G, Schauer R, Tettamanti G: Sialidases in vertebrates: a family of enzymes tailored for several cell functions. Adv Carbohydr Chem Biochem 2010, 64:403-479.

3. Schauer R, Kamerling JP: Chemistry, biochemistry and biology of sialic acids. In Glycoproteins II. Edited by Montreuil J, Vliegenthart JF, Schachte H. Amsterdam: Elsevier Science B.V; 1997:243-402.

4. Schauer R: Sialic acids as regulators of molecular and cellular interactions. Curr Opin Struct Biol 2009, 19:507-514.

5. Miyagi T, Konno K, Emori Y, Kawasaki H, Suzuki K, Yasui A, Tsuik S: Molecular cloning and expression of cDNA encoding rat skeletal muscle cytosolic sialidase. J Biol Chem 1993, 268:26435-26440.

6. Monti E, Preti A, Venerando B, Borsani G: Recent development in mammalian sialidase molecular biology. Neurochem Res 2002, 27:649-663.

7. Achyuthan KE, Achyuthan AM: Comparative enzymology, biochemistry and pathophysiology of human exo-alpha-sialidases (neuraminidases). Comp Biochem Physiol B Biochem Mol Biol 2001, 129:29-64.

8. Miyagi T, Yamaguchi K: Mammalian sialidases: physiological and pathological roles in cellular functions. Glycobiology 2012, 22:880-896.

9. Yu RK, Tsai YT, Ariga T, Yanagisawa M: Structures, biosynthesis, and functions of gangliosides-an overview. J Oleo Sci 2011, 60:537-544.

10. Prinetti A, Loberto N, Chigorno V, Sonnino S: Glycosphingolipid behaviour in complex membranes. Biochim Biophys Acta 2009, 1788:184-193.

11. Yu RK, Nakatani Y, Yanagisawa M: The role of glycosphingolipid metabolism in the developing brain. J Lipid Res 2009, 50(Suppl):S440-S445.

12. Leskawa KC, Erwin RE, Buse PE, Hogan EL: Glycosphingolipid biosynthesis during myogenesis of rat L6 cells in vitro. Mol Cell Biochem 1988, 83:47-54

13. Müthing J, Maurer U, Neumann U, Kniep B, Weber-Schürholz S: Glycosphingolipids of skeletal muscle: I Subcellular distribution of neutral glycosphingolipids and gangliosides in rabbit skeletal muscle. Carbohydr Res 1998, 307:135-145.

14. Müthing J, Maurer U, Weber-Schürholz S: Glycosphingolipids of skeletal muscle: II. Modulation of Ca2(+)-flux in triad membranes by gangliosides. Carbohydr Res 1998, 307:147-157.

15. Cacic M, Sostarić K, Weber-Schürholz S, Müthing J: Immunohistological analyses of neutral glycosphingolipids and gangliosides in normal mouse skeletal muscle and in mice with neuromuscular diseases. Glycoconj J 1995, 12:721-728. 
16. Müthing J, Cacić M: Glycosphingolipid expression in human skeletal and heart muscle assessed by immunostaining thin-layer chromatography. Glycoconj J 1997, 14:19-28.

17. Svennerholm L: Ganglioside designation. Adv Exp Med Biol 1980, 125:11

18. Lopez PH, Schnaar RL: Gangliosides in cell recognition and membrane protein regulation. Curr Opin Struct Biol 2009, 19:549-557.

19. Anderson RG: The caveolae membrane system. Annu Rev Biochem 1998, 67:199-225.

20. Simons K, Toomre D: Lipid rafts and signal transduction. Nat Rev Mol Cell Biol 2000, 1:31-39.

21. Hakomori S, Handa K, Iwabuchi K, Yamamura S, Prinetti A: New insights in glycosphingolipid function: "glycosignaling domain," a cell surface assembly of glycosphingolipids with signal transducer molecules,involved in cell adhesion coupled with signaling. Glycobiology 1998, 8:xi-xix.

22. Kaida K, Ariga T, Yu RK: Antiganglioside antibodies and their pathophysiological effects on Guillain-Barré syndrome and related disorders-a review. Glycobiology 2009, 19:676-692.

23. Suzuki Y: Sialobiology of influenza: molecular mechanism of host range variation of influenza viruses. Biol Pharm Bull 2005, 28:399-408.

24. Jeyakumar M, Butters TD, Dwek RA, Platt FM: Glycosphingolipid lysosomal storage diseases: therapy and pathogenesis. Neuropathol Appl Neurobiol 2002, 28:343-357.

25. D'Azzo A, Bonten E: Molecular mechanisms of pathogenesis in a glycosphingolipid and a glycoprotein storage disease. Biochem Soc Trans 2010, 38:1453-1457.

26. Simpson MA, Cross H, Proukakis C, Priestman DA, Neville DC, Reinkensmeier G, Wang H, Wiznitzer M, Gurtz K, Verganelaki A, Pryde A, Patton MA, Dwek RA, Butters TD, Platt FM, Crosby AH: Infantile-onset symptomatic epilepsy syndrome caused by a homozygous loss-of-function mutation of GM3 synthase. Nat Genet 2004, 36:1225-1229.

27. Inokuchi J: Membrane microdomains and insulin resistance. FEBS Lett 2010, 584:1864-1871.

28. Bernardo A, Harrison FE, McCord M, Zhao J, Bruchey A, Davies SS, Jackson Roberts L, Mathews PM, Matsuoka Y, Ariga T, Yu RK, Thompson R, McDonald MP: Elimination of GD3 synthase improves memory and reduces amyloid-beta plaque load in transgenic mice. Neurobiol Aging 2009, 30:1777-1791

29. Matsuzaki K, Kato K, Yanagisawa K: Abeta polymerization through interaction with membrane gangliosides. Biochim Biophys Acta 2010, 1801:868-877.

30. Paccalet T, Coulombe Z, Tremblay JP: Ganglioside GM3 levels are altered in a mouse model of HIBM: GM3 as a cellular marker of the disease. PLOS One 2010, 5:e10055.

31. Sonnino S, Mauri L, Chigorno V, Prinetti A: Gangliosides as components of lipid membrane domains. Glycobiology 2007, 17:1R-13R.

32. Prokazova NV, Samovilova NN, Gracheva EV, Golovanova NK: Ganglioside GM3 and its biological functions. Biochemistry (Mosc) 2009, 74:235-249.

33. Yamashita T, Hashiramoto A, Haluzik M, Mizukami H, Beck S, Norton A, Kono M, Tsuji S, Daniotti JL, Werth N, Sandhoff R, Sandhoff K, Proia RL: Enhanced insulin sensitivity in mice lacking ganglioside GM3. Proc Natl Acad Sci U S A 2003, 100:3445-3449.

34. Hannun YA, Obeid LM: Principles of bioactive lipid signalling: lessons from sphingolipids. Nat Rev Mol Cell Biol 2008, 9:139-150.

35. Bartke N, Hannun YA: Bioactive sphingolipids: metabolism and function. J Lipid Res 2009, 50(Suppl):S91-S96.

36. Bruni $P$, Donati C: Pleiotropic effects of sphingolipids in skeletal muscle. Cell Mol Life Sci 2008, 65:3725-3736.

37. Monti E, Miyagi T: Structure and function of mammalian sialidases. Top Curr Chem, in press.

38. Trudel GC, Holland PC: Inhibitors of glycoprotein processing act at an early stage of myogenesis. Biochem Biophys Res Commun 1992, 184:125-130.

39. Hoffman EP, Brown RH, Kunkel LM: Dystrophin: the protein product of the Duchenne muscular dystrophy locus. Cell 1987, 51:919-928.

40. Ervasti JM, Campbell KP: A role for the dystrophin-glycoprotein complex as a transmembrane linker between laminin and actin. J Cell Biol 1993, 122:809-823.

41. Michele DE, Campbell KP: Dystrophin-glycoprotein complex: posttranslational processing and dystroglycan function. J Biol Chem 2003, 278:15457-15460

42. Henry MD, Campbell KP: Dystroglycan: an extracellular matrix receptor linked to the cytoskeleton. Curr Opin Cell Biol 1996, 8:625-631.
43. Muntoni F, Torelli S, Wells DJ, Brown SC: Muscular dystrophies due to glycosylation defects: diagnosis and therapeutic strategies. Curr Opin Neurol 2011, 24:437-442.

44. Martin PT, Freeze HH: Glycobiology of neuromuscular disorders. Glycobiology 2003, 13:67R-75R.

45. Barresi R, Campbell KP: Dystroglycan: from biosynthesis to pathogenesis of human disease. J Cell Sci 2006, 119:199-207.

46. Durbeej M, Henry MD, Campbell KP: Dystroglycan in development and disease. Curr Opin Cell Biol 1998, 10:594-601.

47. Zanoteli E, Van de Vlekkert D, Bonten EJ, Hu H, Mann L, Gomero EM, Harris AJ, Ghersi G, D'Azzo A: Muscle degeneration in neuraminidase 1-deficient mice results from infiltration of the muscle fibers by expanded connective tissue. Biochim Biophys Acta 2010, 1802:659-672.

48. Schwetz TA, Norring SA, Ednie AR, Bennett ES: Sialic acids attached to Oglycans modulate voltage-gated potassium channel gating. $J$ Biol Chem 2011, 286:4123-4132.

49. Johnson D, Montpetit ML, Stocker PJ, Bennett ES: The sialic acid component of the beta1 subunit modulates voltage-gated sodium channel function. J Biol Chem 2004, 279:44303-44310.

50. Bonten E, Van der Spoel A, Fornerod M, Grosveld G, D'Azzo A: Characterization of human lysosomal neuraminidase defines the molecular basis of the metabolic storage disorder sialidosis. Genes Dev 1996, 10:3156-3169.

51. Frisch A, Neufeld EF: A rapid and sensitive assay for neuraminidase: application to cultured fibroblasts. Anal Biochem 1979, 95:222-227.

52. Schneider-Jakob HR, Cantz M: Lysosomal and plasma membrane ganglioside GM3 sialidases of cultured human fibroblasts. Differentiation by detergents and inhibitors. Biol Chem Hoppe Seyler 1991, 372:443-450.

53. Fingerhut R, van der Horst GT, Verheijen FW, Conzelmann E: Degradation of gangliosides by the lysosomal sialidase requires an activator protein. Eur J Biochem 1992, 208:623-629.

54. Van der Spoel A, Bonten E, D'Azzo A: Transport of human lysosomal neuraminidase to mature lysosomes requires protective protein/ cathepsin A. EMBO J 1998, 17:1588-1597.

55. Thomas GH: Disorders of glycoprotein degradation and structure: amannosidosis, b-mannosidosis, fucosidosis, and sialidosis. In The Metabolic and Molecular Bases of Inherited Disease, Volume III, 8th edition. Edited by Scriver CR, Beaudet AL, Sly WS, Valle D. New York: McGraw-Hill Inc; 2001:3507-3534.

56. D'Azzo A, Andria G, Strisciuglio P, Galjaard H: Galactosialidosis. In The Metabolic and Molecular Bases of Inherited Disease, Volume III, 8th edition. Edited by Scriver CR, Beaudet AL, Sly WS, Valle D. New York: Mc-Graw-Hill, Inc; 2001:3811-3826.

57. Scriver CR, Beaudet AL, Sly WS, Valle D (Eds): The Metabolic and Molecular Bases of Inherited Disease, $8^{\text {th }}$ edition, Volume 24, Number 4. New York: McGraw-Hill Inc; 2001:519-520.

58. Bonten EJ, Arts WF, Beck M, Covanis A, Donati MA, Parini R, Zammarchi E, D'Azzo A: Novel mutations in lysosomal neuraminidase identify functional domains and determine clinical severity in sialidosis. Hum $\mathrm{Mol}$ Genet 2000, 9:2715-2725

59. Rottier RJ, Bonten E, D'Azzo A: A point mutation in the neu-1 locus causes the neuraminidase defect in the SM/J mouse. Hum Mol Genet 1998, 7:313-321.

60. Champigny MJ, Mitchell M, Fox-Robichaud A, Trigatti BL, Igdoura SA: A point mutation in the neu1 promoter recruits an ectopic repressor, Nkx3.2 and results in a mouse model of sialidase deficiency. Mol Genet Metab 2009, 97:43-52.

61. Potier M, Lu Shun Yan D, Womack JE: Neuraminidase deficiency in the mouse. FEBS Lett 1979, 108:345-348.

62. Andrews NW: Regulated secretion of conventional lysosomes. Trends Cell Biol 2000, 10:316-321.

63. Bossi G, Booth S, Clark R, Davis EG, Liesner R, Richards K, Starcevic M, Stinchcombe J, Trambas C, Dell'Angelica EC, Griffiths GM: Normal lytic granule secretion by cytotoxic T lymphocytes deficient in BLOC-1, -2 and -3 and myosins Va, Vlla and XV. Traffic 2005, 6:243-251

64. Bossi G, Griffiths GM: CTL secretory lysosomes: biogenesis and secretion of a harmful organelle. Semin Immunol 2005, 17:87-94.

65. Jaiswal JK, Andrews NW, Simon SM: Membrane proximal lysosomes are the major vesicles responsible for calcium-dependent exocytosis in nonsecretory cells. J Cell Biol 2002, 159:625-635.

66. Huynh C, Roth D, Ward DM, Kaplan J, Andrews NW: Defective lysosomal exocytosis and plasma membrane repair in Chediak-Higashi/beige cells. Proc Natl Acad Sci U S A 2004, 101:16795-16800. 
67. McNeil PL, Steinhardt RA: Plasma membrane disruption: repair, prevention, adaptation. Annu Rev Cell Dev Biol 2003, 19:697-731.

68. Reddy A, Caler EV, Andrews NW: Plasma membrane repair is mediated by $\mathrm{Ca}(2+)$-regulated exocytosis of lysosomes. Cell 2001, 106:157-169.

69. Roy D, Liston DR, Idone VJ, Di A, Nelson DJ, Pujol C, Bliska JB, Chakrabarti S, Andrews NW: A process for controlling intracellular bacterial infections induced by membrane injury. Science 2004, 304:1515-1518.

70. Yogalingam G, Bonten EJ, Van de Vlekkert D, Hu H, Moshiach S, Connell SA, D'Azzo A: Neuraminidase 1 is a negative regulator of lysosomal exocytosis. Dev Cell 2008, 15:74-86.

71. Burks TN, Cohn RD: Role of TGF- $\beta$ signaling in inherited and acquired myopathies. Skelet Muscle 2011, 1:19.

72. Zhu J, Li Y, Shen W, Qiao C, Ambrosio F, Lavasani M, Nozaki M, Branca MF, Huard J: Relationships between transforming growth factor-beta1, myostatin, and decorin: implications for skeletal muscle fibrosis. $J$ Biol Chem 2007, 282:25852-25863.

73. Li ZB, Zhang J, Wagner KR: Inhibiting myostatin reverses muscle fibrosis through apoptosis. $J$ Cell SCi, in press.

74. Li ZB, Kollias HD, Wagner KR: Myostatin directly regulates skeletal muscle fibrosis. J Biol Chem 2008, 283:19371-19378

75. Artaza JN, Singh R, Ferrini MG, Braga M, Tsao J, Gonzalez-Cadavid NF: Myostatin promotes a fibrotic phenotypic switch in multipotent $\mathrm{C} 3 \mathrm{H}$ 10T1/2 cells without affecting their differentiation into myofibroblasts. $J$ Endocrinol 2008, 196:235-249.

76. Hinek A, Pshezhetsky AV, von Itzstein M, Starcher B: Lysosomal sialidase (neuraminidase-1) is targeted to the cell surface in a multiprotein complex that facilitates elastic fiber assembly. J Biol Chem 2006, 281:3698-3710.

77. Pshezhetsky AV, Hinek A: Where catabolism meets signalling: neuraminidase 1 as a modulator of cell receptors. Glycoconj J 2011, 28:441-452.

78. Starcher B, D'Azzo A, Keller PW, Rao GK, Nadarajah D, Hinek A: Neuraminidase- 1 is required for the normal assembly of elastic fibers. Am J Physiol Lung Cell Mol Physiol 2008, 295:L637-L647.

79. Uemura T, Shiozaki K, Yamaguchi K, Miyazaki S, Satomi S, Kato K, Sakuraba $H$, Miyagi T: Contribution of sialidase NEU1 to suppression of metastasis of human colon cancer cells through desialylation of integrin beta4. Oncogene 2009, 28:1218-1229.

80. Dennis JW, Granovsky M, Warren CE: Glycoprotein glycosylation and cancer progression. Biochim Biophys Acta 1999, 1473:21-34.

81. Hinek A, Bodnaruk TD, Bunda S, Wang Y, Liu K: Neuraminidase-1, a subunit of the cell surface elastin receptor, desialylates and functionally inactivates adjacent receptors interacting with the mitogenic growth factors PDGF-BB and IGF-2. Am J Pathol 2008, 173:1042-1056.

82. Arabkhari M, Bunda S, Wang $Y$, Wang $A$, Pshezhetsky AV, Hinek A: Desialylation of insulin receptors and IGF-1 receptors by neuraminidase1 controls the net proliferative response of L6 myoblasts to insulin. Glycobiology 2010, 20:603-616.

83. Champigny MJ, Johnson M, Igdoura SA: Characterization of the mouse lysosomal sialidase promoter. Gene 2003, 319:177-187.

84. Champigny MJ, Perry R, Rudnicki M, Igdoura SA: Overexpression of MyoDinducible lysosomal sialidase (neu1) inhibits myogenesis in C2C12 cells. Exp Cell Res 2005, 311:157-166.

85. Xu Z, Weiss A: Negative regulation of CD45 by differential homodimerization of the alternatively spliced isoforms. Nat Immunol 2002, 3:764-771

86. Polesskaya A, Seale $P$, Rudnicki MA: Wnt signaling induces the myogenic specification of resident CD45+ adult stem cells during muscle regeneration. Cell 2003, 113:841-852.

87. Lee YN, Kang JS, Krauss RS: Identification of a role for the sialomucin CD164 in myogenic differentiation by signal sequence trapping in yeast. Mol Cell Biol 2001, 21:7696-7706.

88. Suzuki M, Angata K, Nakayama J, Fukuda M: Polysialic acid and mucin type o-glycans on the neural cell adhesion molecule differentially regulate myoblast fusion. J Biol Chem 2003, 278:49459-49468.

89. Akita H, Miyagi T, Hata K, Kagayama M: Immunohistochemical evidence for the existence of rat cytosolic sialidase in rat skeletal muscles. Histochem Cell Biol 1997, 107:495-503.

90. Miyagi T, Tsuiki S: Purification and characterization of cytosolic sialidase from rat liver. J Biol Chem 1985, 260:6710-6716.

91. Kijimoto-Ochiai S, Koda T, Suwama T, Matsukawa H, Fujii M, Tomobe K, Nishimura M: Low expression of Neu2 sialidase in the thymus of SM/J mice-existence of neuraminidase positive cells "Neu-medullocyte" in the murine thymus. Glycoconj J 2008, 25:787-796.

92. Monti E, Preti A, Rossi E, Ballabio A, Borsani G: Cloning and characterization of NEU2, a human gene homologous to rodent soluble sialidases. Genomics 1999, 57:137-143.

93. Monti E, Preti A, Nesti C, Ballabio A, Borsani G: Expression of a novel human sialidase encoded by the NEU2 gene. Glycobiology 1999, 9:1313-1321.

94. Chavas LM, Tringali C, Fusi P, Venerando B, Tettamanti G, Kato R, Monti E, Wakatsuki S: Crystal structure of the human cytosolic sialidase Neu2. Evidence for the dynamic nature of substrate recognition. J Biol Chem 2005, 280:469-475.

95. Taylor G: Sialidases: structures, biological significance and therapeutic potential. Curr Opin Struct Biol 1996, 6:830-837.

96. Tringali C, Papini N, Fusi P, Croci G, Borsani G, Preti A, Tortora P, Tettamanti $G$, Venerando B, Monti E: Properties of recombinant human cytosolic sialidase HsNEU2. The enzyme hydrolyzes monomerically dispersed GM1 ganglioside molecules. J Biol Chem 2004, 279:3169-3179.

97. Sato K, Miyagi T: Genomic organization and the 5'-upstream sequence of the rat cytosolic sialidase gene. Glycobiology 1995, 5:511-516.

98. Fanzani A, Giuliani R, Colombo F, Zizioli D, Presta M, Preti A, Marchesini S: Overexpression of cytosolic sialidase Neu2 induces myoblast differentiation in C2C12 cells. FEBS Lett 2003, 547:183-188.

99. Sato K, Miyagi T: Involvement of an endogenous sialidase in skeletal muscle cell differentiation. Biochem Biophys Res Commun 1996, 221:826-830.

100. Musarò A, McCullagh K, Paul A, Houghton L, Dobrowolny G, Molinaro M, Barton ER, Sweeney HL, Rosenthal N: Localized lgf-1 transgene expression sustains hypertrophy and regeneration in senescent skeletal muscle. Nat Genet 2001, 27:195-200.

101. Scicchitano BM, Spath L, Musarò A, Molinaro M, Rosenthal N, Nervi C, Adamo S: Vasopressin-dependent myogenic cell differentiation is mediated by both $\mathrm{Ca} 2+/$ calmodulin-dependent kinase and calcineurin pathways. Mol Biol Cell 2005, 16:3632-3641.

102. lezzi S, Di Padova M, Serra C, Caretti G, Simone C, Maklan E, Minetti G, Zhao $P$, Hoffman EP, Puri PL, Sartorelli V: Deacetylase inhibitors increase muscle cell size by promoting myoblast recruitment and fusion through induction of follistatin. Dev Cell 2004, 6:673-684.

103. Fanzani A, Colombo F, Giuliani R, Preti A, Marchesini S: Insulin-like growth factor 1 signaling regulates cytosolic sialidase Neu2 expression during myoblast differentiation and hypertrophy. FEBS J 2006, 273:3709-3721.

104. Fanzani A, Giuliani R, Colombo F, Rossi S, Stoppani E, Martinet W, Preti A Marchesini S: The enzymatic activity of sialidase Neu2 is inversely regulated during in vitro myoblast hypertrophy and atrophy. Biochem Biophys Res Commun 2008, 370:376-381.

105. Glass DJ: PI3 kinase regulation of skeletal muscle hypertrophy and atrophy. Curr Top Microbiol Immunol 2010, 346:267-278.

106. Sandri M: Signaling in muscle atrophy and hypertrophy. Physiology (Bethesda) 2008, 23:160-170.

107. Rossi S, Stoppani E, Martinet W, Bonetto A, Costelli P, Giuliani R, Colombo F, Preti A, Marchesini S, Fanzani A: The cytosolic sialidase Neu2 is degraded by autophagy during myoblast atrophy. Biochim Biophys Acta 2009, 1790: 817-828.

108. Bechet D, Tassa A, Taillandier D, Combaret L, Attaix D: Lysosomal proteolysis in skeletal muscle. Int J Biochem Cell Biol 2005, 37:2098-2114.

109. Stoppani E, Rossi S, Marchesini S, Preti A, Fanzani A: Defective myogenic differentiation of human rhabdomyosarcoma cells is characterized by sialidase Neu2 loss of expression. Cell Biol Int 2009, 33:1020-1025.

110. De Giovanni C, Landuzzi L, Nicoletti G, Lollini PL, Nanni P: Molecular and cellular biology of rhabdomyosarcoma. Future Oncol 2009, 5:1449-1475

111. Barr FG: The role of chimeric paired box transcription factors in the pathogenesis of pediatric rhabdomysarcoma. Cancer Res 1999, 59:1711s-1715s

112. Merlino G, Helman L: Rhabdomyosarcoma-working out the pathways. Oncogene 1999, 18:5340-5348.

113. Zanola A, Rossi S, Faggi F, Monti E, Fanzani A: Rhabdomyosarcomas: an overview on the experimental animal models. J Cell Mol Med 2012, 16:1377-1379.

114. Suzuki N, Aoki M, Hinuma Y, Takahashi T, Onodera Y, Ishigaki A, Kato M, Warita $H$, Tateyama M, Itoyama $Y$ : Expression profiling with progression of dystrophic change in dysferlin-deficient mice (SJL). Neurosci Res 2005, 52:47-60.

115. Ishizuka A, Hashimto Y, Naka R, Kinoshita M, Kakehi K, Seino J, Funakoshi Y, Suzuki T, Kameyama A, Narimatsu H: Accumulation of free complex-type 
N-glycans in MKN7 and MKN45 stomach cancer cells. Biochem J 2008, 413:227-237.

116. Martin PT: Mechanisms of disease: congenital muscular dystrophiesglycosylation takes center stage. Nat Clin Pract Neurol 2006, 2:222-230.

117. Belaya K, Finlayson S, Slater CR, Cossins J, Liu WW, Maxwell S, McGowan SJ, Maslau S, Twigg SR, Walls TJ, Pascual Pascual SI, Palace J, Beeson D: Mutations in DPAGT1 Cause a Limb-Girdle Congenital Myasthenic Syndrome with Tubular Aggregates. Am J Hum Genet 2012, 91:193-201.

118. Oehler C, Kopitz J, Cantz M: Substrate specificity and inhibitor studies of a membrane-bound ganglioside sialidase isolated from human brain tissue. Biol Chem 2002, 383:1735-1742.

119. Ha KT, Lee YC, Cho SH, Kim JK, Kim CH: Molecular characterization of membrane type and ganglioside-specific sialidase (Neu3) expressed in E. coli. Mol Cells 2004, 17:267-273.

120. Miyagi T, Wada T, Iwamatsu A, Hata K, Yoshikawa Y, Tokuyama S, Sawada M: Molecular cloning and characterization of a plasma membrane-associated sialidase specific for gangliosides. J Biol Chem 1999, 274:5004-5011.

121. Monti E, Bassi MT, Papini N, Riboni M, Manzoni M, Venerando B, Croci G, Preti A, Ballabio A, Tettamanti G, Borsani G: Identification and expression of NEU3, a novel human sialidase associated to the plasma membrane. Biochem J 2000, 349:343-351.

122. Zanchetti G, Colombi P, Manzoni M, Anastasia L, Caimi L, Borsani G, Venerando B, Tettamanti G, Preti A, Monti E, Bresciani R: Sialidase NEU3 is a peripheral membrane protein localized on the cell surface and in endosomal structures. Biochem J 2007, 408:211-219.

123. Papini N, Anastasia L, Tringali C, Croci G, Bresciani R, Yamaguchi K, Miyagi T, Preti A, Prinetti A, Prioni S, Sonnino S, Tettamanti G, Venerando B, Monti E: The plasma membrane-associated sialidase MmNEU3 modifies the ganglioside pattern of adjacent cells supporting its involvement in cellto-cell interactions. J Biol Chem 2004, 279:16989-16995.

124. Li XM, Momsen MM, Brockman HL, Brown RE: Lactosylceramide: effect of acyl chain structure on phase behavior and molecular packing. Biophys J 2002, 83:1535-1546.

125. Mukai A, Kurisaki T, Sato SB, Kobayashi T, Kondoh G, Hashimoto N: Dynamic clustering and dispersion of lipid rafts contribute to fusion competence of myogenic cells. Exp Cell Res 2009, 315:3052-3063.

126. Sasaki A, Hata K, Suzuki S, Sawada M, Wada T, Yamaguchi K, Obinata M, Tateno H, Suzuki H, Miyagi T: Overexpression of plasma membraneassociated sialidase attenuates insulin signaling in transgenic mice. J Biol Chem 2003, 278:27896-27902.

127. Wada T, Hata K, Yamaguchi K, Shiozaki K, Koseki K, Moriya S, Miyagi T: A crucial role of plasma membrane-associated sialidase in the survival of human cancer cells. Oncogene 2007, 26:2483-2490.

128. Kato K, Shiga K, Yamaguchi K, Hata K, Kobayashi T, Miyazaki K, Saijo S, Miyagi T: Plasma-membrane-associated sialidase (NEU3) differentially regulates integrin-mediated cell proliferation through laminin- and fibronectin-derived signalling. Biochem J 2006, 394:647-656.

129. Miyagi T, Wada T, Yamaguchi K, Shiozaki K, Sato I, Kakugawa Y, Yamanami $\mathrm{H}$, Fujiya T: Human sialidase as a cancer marker. Proteomics 2008, 8:3303-3311.

130. Miyagi T, Wada T, Yamaguchi K, Hata K, Shiozaki K: Plasma membraneassociated sialidase as a crucial regulator of transmembrane signalling. J Biochem 2008, 144:279-285.

131. Kalka D, von Reitzenstein C, Kopitz J, Cantz M: The plasma membrane ganglioside sialidase cofractionates with markers of lipid rafts. Biochem Biophys Res Commun 2001, 283:989-993.

132. Wang Y, Yamaguchi K, Wada T, Hata K, Zhao X, Fujimoto T, Miyagi T: A close association of the ganglioside-specific sialidase Neu3 with caveolin in membrane microdomains. J Biol Chem 2002, 277:26252-26259.

133. Czech MP: Lipid rafts and insulin action. Nature 2000, 407:147-148.

134. Yoshizumi S, Suzuki S, Hirai M, Hinokio Y, Yamada T, Tsunoda U, Aburatani $H$, Yamaguchi K, Miyagi T, Oka Y: Increased hepatic expression of ganglioside-specific sialidase, NEU3, improves insulin sensitivity and glucose tolerance in mice. Metabolism 2007, 56:420-429.

135. Miljan EA, Meuillet EJ, Mania-Farnell B, George D, Yamamoto H, Simon HG, Bremer EG: Interaction of the extracellular domain of the epidermal growth factor receptor with gangliosides. J Biol Chem 2002, 277:10108-10113.

136. Coskun Ü, Grzybek M, Drechsel D, Simons K: Regulation of human EGF receptor by lipids. Proc Natl Acad Sci U S A 2011, 108:9044-9048.

137. Anastasia L, Papini N, Colazzo F, Palazzolo G, Tringali C, Dileo L, Piccoli M, Conforti E, Sitzia C, Monti E, Sampaolesi M, Tettamanti G, Venerando B:
NEU3 sialidase strictly modulates GM3 levels in skeletal myoblasts $\mathrm{C} 2 \mathrm{C} 12$ thus favoring their differentiation and protecting them from apoptosis. J Biol Chem 2008, 283:36265-36271.

138. Papini N, Anastasia L, Tringali C, Dileo L, Carubelli I, Sampaolesi M, Monti E, Tettamanti G, Venerando B: MmNEU3 sialidase over-expression in C2C12 myoblasts delays differentiation and induces hypertrophic myotube formation. J Cell Biochem 2012, 113:2967-2978.

139. Sabourin LA, Rudnicki MA: The molecular regulation of myogenesis. Clin Genet 2000, 57:16-25.

140. Le Grand F, Rudnicki MA: Skeletal muscle satellite cells and adult myogenesis. Curr Opin Cell Biol 2007, 19:628-633.

141. Fanzani A, Conraads VM, Penna F, Martinet W: Molecular and cellular mechanisms of skeletal muscle atrophy: an update. J Cachexia Sarcopenia Muscle 2012, 3:163-179.

142. Cohn RD, Campbell KP: Molecular basis of muscular dystrophies. Muscle Nerve 2000, 23:1456-1471.

143. Thomas DR: Loss of skeletal muscle mass in aging: examining the relationship of starvation, sarcopenia and cachexia. Clin Nutr 2007, 26:389-399.

144. Varki A, Cummings RD, Esko JD, Freeze HH, Stanley P, Bertozzi CR, Hart GW Etzler ME: Essentials of Glycobiology. 2nd edition. Cold Spring Harbor (NY): Cold Spring Harbor Laboratory Press; 2009.

doi:10.1186/2044-5040-2-23

Cite this article as: Fanzani et al: Implications for the mammalian sialidases in the physiopathology of skeletal muscle. Skeletal Muscle 2012 2:23.

\section{Submit your next manuscript to BioMed Central and take full advantage of:}

- Convenient online submission

- Thorough peer review

- No space constraints or color figure charges

- Immediate publication on acceptance

- Inclusion in PubMed, CAS, Scopus and Google Scholar

- Research which is freely available for redistribution 